Barbara Morel, Une iconographie de la répression judiciaire. Le châtiment dans l'enluminure en France du $\mathrm{XIII}^{e}$ au XV $\mathrm{XV}^{e}$ siècle, Paris, Comité des Travaux historiques et scientifiques, 2007

\title{
Léonard Dauphant
}

\section{OpenEdition}

Journals

Édition électronique

URL : http://journals.openedition.org/questes/443

DOI : 10.4000 /questes.443

ISSN : 2109-9472

Éditeur

Les Amis de Questes

\section{Édition imprimée}

Date de publication : 15 mars 2008

Pagination : 94-98

ISSN : 2102-7188

\section{Référence électronique}

Léonard Dauphant, «Barbara Morel, Une iconographie de la répression judiciaire. Le châtiment dans l'enluminure en France du xII ${ }^{e}$ au xv siècle, Paris, Comité des Travaux historiques et scientifiques, 2007 ", Questes [En ligne], 14 | 2008, mis en ligne le 01 janvier 2014, consulté le 24 septembre 2020. URL: http://journals.openedition.org/questes/443 ; DOl : https://doi.org/10.4000/questes.443 


\section{Barbara MOREL, Une iconographie de la répression judiciaire. Le châtiment dans l'enluminure en France du XIII ${ }^{e}$ au $\mathrm{XV}^{e}$ siècle, Paris, Comité des Travaux historiques et scientifiques, 2007}

\section{compte rendu par Léonard DAUPHANT}

\section{Choix du corpus iconographique et méthodologie}

L'ouvrage de Barbara Morel $^{1}$ est la reprise d'une thèse soutenue à Paris I en 2003 sous la direction de Léon Pressouyre. Elle s'inscrit partiellement dans une recherche iconologique centrée sur la justice divine ${ }^{2}$ mais veut aller au-delà de l'idée traditionnelle d'une justice des hommes solidaire d'une justice de Dieu liée aux châtiments infernaux.

Le corpus comprend 763 images, toutes consultées directement selon L. Pressouyre, ce qui a ainsi permis à l'auteur de découvrir des marginalia non reproduites dans les fichiers numériques.

Ces 763 images proviennent de 304 manuscrits, dont 121 images sur 78 manuscrits juridiques, centraux pour le sujet mais livres de travail pauvres en illustrations, et 140 illustrations de prison. Le corpus ne se limite pas aux ouvrages de droit, mais s'ouvre à l'ensemble de la production écrite, par exemple les chroniques, pour déceler le va-et-vient entre réalité et imaginaire au sein de chaque corpus. Dans le domaine du droit par exemple, l'iconographie n'est pas une illustration neutre ou « objective », mais participe d'une stratégie

\footnotetext{
1 Barbara MOREL, Une iconographie de la répression judiciaire. Le châtiment dans l'enluminure en France du XIII au XV siècle, Paris, Comité des Travaux historiques et scientifiques, 2007.

${ }^{2}$ Cf. Jérôme BASCHET, Les justices de l'au-delà. Les représentations de l'enfer en France et en Italie (XII $-X V^{e}$ siècle), Paris, EHESS, 1989, et Wolfgang PLEISTER et Wolfgang SCHILD, Recht und Gerechtigkeit im Spiegel der europäischen Kunst, Köln, DuMont, 1988.
} 
répressive. Inversement, l'auteur montre la valeur documentaire, peut-être inattendue, de certaines images de chroniques. Il s'agit donc d'étudier ensemble enluminure, littérature, archéologie et sources normatives pour déterminer un imaginaire du supplice et de la peine, de la violence légale.

Si la prison participe de la répression, on notera le refus explicite d'intégrer dans le corpus ce qui a trait à l'iconographie du martyre, bien différente de celle de la répression judiciaire. Ces deux réalités convergent dans une démonstration de ferveur religieuse mais opposent le pécheur et le saint, induisant des représentations figurées aux stéréotypes bien divergents. Dans un cas, le bourreau n'est que l'instrument de l'exécution d'un coupable par les autorités ; dans l'autre, la présence du bourreau-tyran est centrale mais c'est Dieu qui en définitive décide du moment de la mort du saint. Le repentir du coupable s'oppose à la victimisation de l'innocent glorifié par sa souffrance.

Le choix du corpus comme la précision de ses analyses nous semblent être un véritable modèle de recherche iconologique, qui veille également à s'ouvrir vers les autres domaines de la recherche: histoire des textes, du droit, archéologie.

\section{Les stéréotypes de la répression justifiée}

L'intérêt de l'étude réside d'abord dans la mise en évidence d'une répression à la fois mise en valeur et édulcorée. Loin de l'imagerie macabre attendue, s'impose au contraire un «châtiment aseptisé ». Ici, l'auteur rappelle opportunément qu'au-delà de son corpus renfermé au secret des livres, l'omniprésence des gibets dans le paysage manifestait puissamment l'existence de la justice vindicative. Domine au contraire un stéréotype peut-être largement émané du milieu judiciaire lui-même : un criminel repentant, une mort consentie et sans horreur. Le pardon et l'absolution servent de caution au supplice, devenu possibilité de rédemption. Quelle meilleure justification de la répression que de la faire entrer dans une logique de rachat des condamnés? 
En revanche, la représentation de la prison est unanimement effroyable, illustrée et pensée comme une peine. Ici se situe un fossé entre le droit et les représentations communes ${ }^{3}$. Les images du corpus entrent en consonance avec l'hagiographie (pensons aux saints Léonard ou Nicolas qui suscitent des évasions miraculeuses, pour l'innocent mais aussi pour le coupable) qui présente le prisonnier comme un pénitent, mais également avec la littérature : l'épreuve de la prison est un moment fort et terrible pour les chevaliers arthuriens.

\section{Une large acceptation sociale?}

L'iconographie de la répression judiciaire témoigne d'un large consensus pour une justice rigoureuse. On peut opposer ces conclusions aux lieux communs du temps affirmant que la justice se doit d'être plus «miséricordieuse » que «crueuse ». Certes, le châtiment est vu partiellement sous l'angle corporatif des juges, professionnels de la répression, mais il illustre aussi, plus largement, un «désir de justice, aboutissement d'une répression idéale sachant punir avec discernement pour le plus grand bien de tous ${ }^{4} . »$ Il faut souligner que la répression judiciaire aboutissant à la peine capitale constitue l'extrême de la justice, ce qui ne contredit pas absolument les affirmations sur la justice miséricordieuse ou sur la nécessité des compromis para-judiciaires pour éviter, justement, « rigueur de justice ». La répression s'auto-justifie car elle se pense comme la nécessité de punir fermement, une fois que le travail social de résolution des conflits a échoué, où que le crime est patent. Dans ce cas d'aspiration à la répression comme ultime moyen de préserver l'ordre terrestre, on voit même apparaître des occurrences, rares, d'un usage positif du mot « cruauté », comme ce distique d'Alart de Cambrai (XIII ${ }^{\mathrm{e}}$ siècle) :

\footnotetext{
${ }^{3}$ Avec le droit civil : contrairement aux théories de Michel Foucault sur l'invention de la peine de prison induite par les Lumières, la peine de réclusion est en usage, bien avant l'époque moderne, dans la justice ecclésiastique. Mais aussi avec le droit ecclésiastique, pour qui la réclusion a une valeur probatoire, comme dans notre système judiciaire contemporain. Manifestement, les représentations communes ne participaient à aucune de ces logiques.

${ }^{4}$ Barbara MOREL, op. cit., p. 31.
} 
« Seroit la terre mal baillie, se cruautez estoit faillie. $»^{5}$

\section{Contrepoint : les mauvaises justices}

À cette foi dans la justice royale s'opposent de mauvaises justices et des peines unanimement condamnées. Quand l'époque et le lieu représenté changent, la vision du châtiment subit un traitement différent : la violence impie des musulmans rejoint en fait les stéréotypes de l'iconographie des martyrs antiques, quand, par exemple, sont représentées les mises à mort de chrétiens crucifiés pour leur foi. Hors de tout témoignage religieux, c'est la cruauté des châtiments en usage chez les Byzantins et les Mérovingiens qui est condamnée dans la mise en scène des images elle-même (représentation d'écartèlements). La justice romaine subit un traitement plus complaisant: les scènes de crucifixion nous montrent des suppliciés aux bras attachés par des cordes, pour éviter de créer un lien avec la crucifixion du Christ et de ses martyrs, et donc une empathie avec les condamnés. La violence est donc largement manipulée, édulcorée quand elle se veut acceptable et juste, beaucoup plus crue quand il s'agit de la dénoncer.

Face au rituel du châtiment accepté et légal, face à la justice inutilement cruelle ou perverse de l'ailleurs ou du passé, les miniatures (principalement anglaises) du Roman de Renart offrent un rare et unique contrepoint, celle d'une justice ridicule, incapable d'une répression effective. Renart échappe toujours au gibet, il se moque de la mollesse du roi impuissant. Cette justice d'amateurs se contente de faire des exemples pendant que les plus malins lui échappent.

\section{Visions modernes de la répression judiciaire médiévale}

L'occultation du macabre dans le discours iconographique fait contraste avec notre préjugé concernant la complaisance médiévale pour l'horreur des

\footnotetext{
${ }^{5}$ Cité, ibid., p. 21.
} 
châtiments. L'ouvrage se termine sur une brève étude de la vision romantique et libérale de la répression médiévale, qui, en fait, retourne involontairement contre «l'obscurantisme» les artifices de l'iconographie du martyre. Dans cette « imagerie républicaine » de la peinture pompier sont indispensables la torture, l'omniprésence du clergé et du bourreau, ainsi qu'une foule haineuse et avide de sang. Si ces représentations sont à inscrire dans le combat libéral du XIX ${ }^{\mathrm{e}}$ siècle contre les survivances de la justice d'Ancien Régime (les mutilations réintroduites dans le droit par Napoléon sont supprimées en 1832, comme la marque au fer rouge), elles forment un imaginaire encore bien vivant ${ }^{6}$, mais bien différent de ce que dégage le corpus, où se déploie au contraire l'expression d'une justice civile où la piété a sa place (mais non le clergé), largement acceptée mais édulcorée comme un mal nécessaire.

\footnotetext{
${ }^{6}$ Il y a quelques années, un sénateur faisait (re- ?) construire à Loches une des « cages » de Louis XI, tout à fait dans l'esprit des «musées de la torture ».
} 